\title{
Strengths-based student-led presentations in clinical reflection seminars: Narratives of learning experiences
}

\author{
Ping Zou*1, Lauren Easton ${ }^{1}$, Emily Mudrick ${ }^{1}$, Stephanie Grzelak ${ }^{1}$, Rick Vanderlee ${ }^{2}$ \\ ${ }^{1}$ School of Nursing, Nipissing University, Toronto, Ontario, Canada \\ ${ }^{2}$ Faculty of Applied and Professional Study, Nipissing University, Toronto, Ontario, Canada
}

Received: August 1, 2017

DOI: $10.5430 /$ jnep.v8n3p48
Accepted: October 22, $2017 \quad$ Online Published: November 2, 2017

URL: https://doi.org/10.5430/jnep.v8n3p48

\begin{abstract}
According to the strengths-based care theory, the strengths-based student-led presentation was designed and implemented in order to improve learning and teaching experiences in clinical reflection seminars. This paper describes learning experiences of both the instructor and the learners, explores common narrative themes, and discusses future implications of strengths-based applications in undergraduate nursing education. Through reflection on learning experiences, four themes, including creating a caring and empathetic learning environment, an open self-directed curriculum design, reciprocal learning, and leadership to influence peers and practicum, have been explored.
\end{abstract}

Key Words: Strengths-based care theory, Student-led learning, Clinical reflection seminars, Narrative inquiry, Nursing education, Open self-directed curriculum

\section{INTRODUCTION}

Responding to a constantly changing Canadian health care environment ${ }^{[1]}$ and the need for a new generation of nurses and nursing practice, ${ }^{[2]}$ the Scholar Practitioner Program was designed to be an innovative second-degree entry Bachelor of Science in Nursing that students complete in six semesters over two full calendar years in a metropolitan area in Canada. The premise of the program is that nurses need to be both clinically competent and theoretically sound as "scholar practitioners". This program prepares graduates to work in a holistic healing relationship, to serve individuals and communities locally and internationally, and to generate new knowledge to support inter-professional health care practice. Four curriculum themes are threaded throughout the program, including nurse-client relationship, narrative inquiry, scholarship, and health. The program's curriculum unfolds through the use of William Doll's four R's: recursion, richness, relations, and rigor. ${ }^{[3]}$ The graduates from this second-degree program are expected to exhibit the following professional characteristics: curious, insightful, technologically competent, courageous, and knowledgeable. ${ }^{[4]}$

Clinical reflection seminars are essential components of this program. Without the traditional concept of independent courses, every semester is 13 weeks long and composed of three weeks of classroom inquiry, nine weeks of clinical practicum, and one week of in-class reflection. A clinical reflection seminar runs for four hours every week over the nine-week clinical practicum period. Clinical reflection seminars are expected to bridge learning gaps and support students' learning experiences throughout the clinical period. ${ }^{[5,6]}$ However, there is a learning curve from the class-

\footnotetext{
*Correspondence: Ping Zou; Email: pingz@ nipissingu.ca; Address: School of Nursing, Nipissing University, 750 Dundas Street West, Room 209, Toronto, Ontario, Canada.
} 
room to clinical practicum: some students stated that clinical reflection seminars lacked content, were not efficiently run, and were disconnected from their learning needs. Some students were bored, dissatisfied, and unwilling to come to reflection seminars. There is an urgent need to explore an effective approach to optimise reflection seminars in order to ensure that they remain engaging and safe learning environments that are relevant to practice. According to the strengths-based care theory, ${ }^{[7]}$ the student-led presentation format in clinical seminars was designed, implemented and evaluated in order to improve learning and teaching experiences of reflection seminars. The purpose of this paper is to reflect on and share the experiences of an instructor and her students in this innovative learning activity. This paper describes learning experiences, common narrative themes, and explores future implications of strengths-based applications in undergraduate nursing education.

\section{THEORETICAL FRAMEWORK}

The strengths-based nursing theory has been used to develop this learning activity. Strengths-based nursing is an approach that promotes empowerment, self-efficacy and hope by focusing on an individual's inner and outer strengths. ${ }^{[8]}$ Strengths-based nursing has been discussed in literature in the context of providing nursing care and in fostering transformational leadership. ${ }^{[7]}$ Nursing educators also started to explore strengths-based strategies in nursing education, where modern undergraduate students experience significant levels of stress and anxiety. A study using a strengths-based approach in clinical teaching suggested that this approach promotes student empowerment, collaborative learning, and mutual growth. ${ }^{[9]}$ Informed by experiences of this study, we explored the design and implementation of a strengths-based activity during clinical reflection seminars.

\section{METHODS}

Narrative inquiry framework has been applied as the andragogy for students and the instructor to design, implement and reflect on this innovative learning activity. ${ }^{[10]}$ The assumption of narrative inquiry methodology is that human lives are composed of stories and we live by reflecting on our stories. A narrative inquiry starts from a meaningful story in which we are involved and which impacts our lives. Reflection is considered a significant process to deepen our understanding of life events, and facilitate our learning and growth. Narrative inquiry could lead to changes in our professional practice in the future. ${ }^{[11]}$

The strengths-based student-led presentations have been practiced in reflection seminars among a total of 40 students in four academic semesters. Three students volunteered to

Published by Sciedu Press reflect on their learning experience and co-authorize this paper. Three students were self-identified as female, in the age group from 24 to 27 , had a health-related first university degree, and were pursing Bachelor degree of Nursing as their second degree. At the end of the semester, after completing all strengths-based student-led presentations and all academic evaluations, the instructor and three students reflected on their collective learning experiences. The instructor provided three students a one-page reflection guide with a list of guiding questions. Students were encouraged to reflect in their own way with guiding questions serving as a reference. The instructor and students wrote their reflections independently. Once completed, all reflections were shared and common themes were found. The instructor and three students consented to share their experiences in this paper to facilitate the discussion of strengths-based nursing education. It was aware of that an instructor is positioned in a place of power in the traditional educator-student relationship. Thus, all reflection processes were conducted at the end of semester after all evaluations had been completed. Both the instructor and the students understood that reflections were voluntary activities which would not impact students' current and future academic evaluations.

\section{INSTRUCTOR'S NARRATIVE: WHY STRENGTHS-BASED?}

I was pushed by my students to create this strengths-based student-led learning activity. I am an adult educator with national and international teaching experiences where I have been trained to provide students with both positive and negative feedback. I was taught that negative feedback could lead to improvement and positive feedback might not. As an instructor, I believed I had to criticize students' work in order to help them improve. I appreciated the saying, "no pain, no gain", and believed it explains the necessity of hard work. These were my teaching concepts, which were changed by a student comment. Two years ago, among a large amount of positive student evaluations, one student wrote: "There are some talks of if we are not doing something we will get a Failure. This is not the good way to teach students." I am a reflective instructor who welcomes feedback and embraces professional development. I asked myself, if my students do not want to hear about failure, what do they want to hear? If negative feedback is not well accepted, what kind of feedback should I use to improve students' learning? How can I build a better learning environment for my students and myself? Is there a way to involve no pain while everyone still gains?

While I was looking for the answers to the questions above, a student applied strengths-based theory in her nursing care 
in clinical practice. Stimulated by her practice, I designed this strengths-based learning activity. Intuitively, I think this theory might guide my innovation. Guided by current literature on strengths-based theory, I created my strengthsbased teaching philosophies, including (a) all learners have strengths and weaknesses; (b) focusing on strengths empowers learners, while overstressing weaknesses can defeat learners; (c) learners' strengths can be used to meet each other's learning needs; (d) strengths-based teaching promotes a safe and motivated learning environment; and (e) strengths are constructive elements which lead to everyone's success in the learning process.

Built upon my strengths-based teaching philosophies, I designed this activity. At the beginning of every semester, I conducted student needs assessments in order to understand my students' past experiences, current needs and future goals. Then I presented my activity design to the clinical practicum group and requested feedback. By group discussion, all group members collectively decided if this activity met their learning needs and if it was feasible and meaningful to conduct in clinical reflection seminars. This learning activity includes six steps: every student (a) chooses a meaningful topic based on the strengths, (b) negotiates within the group about the topic and others' learning needs, (c) prepares an evidence-based presentation, (d) uses different approaches to deliver the presentation, (e) leads the group to practice NCLEX questions related to the presentation, and finally (f) the group members credit the presenter by writing a thank you card.

To summarize, innovative teaching strategies are essential to teaching in an innovative era. This is common sense; however, sometimes, our teaching strategies are left behind. Instructors fail to update their teaching strategies because: they are unaware of students' new needs; they have been trained to teach in this way; they are unsure about the success of new teaching methods with limited evidence; they are afraid of the failure of new teaching trials, which might lead to criticism from colleagues; etc. Fortunately, self-reflection and evidence-based teaching can facilitate us in finding innovative teaching approaches.

\section{A LEARNER'S NARRATIVE ON SEXUALLY TRANSMITTED INFECTIONS PRESENTA- TION}

When we first met as a group in our weekly reflection seminar, the strengths-based mentality was implemented and celebrated. Our instructor asked that each of us record our short-term and long-term goals as nurses. This brief exercise offered an opportunity to reflect on our individual trajecto- ries, while reinforcing that our instructor had a vested interest in our success and wellbeing. As we discussed these goals in the small group, it became apparent that our instructor wanted us to realize our potential, and this quickly made us accountable and inspired.

I chose to create a presentation on sexually transmitted infections because it was applicable to my practicum at the Sexual Health Clinic within a large metropolitan city's public health organization. In choosing this topic, I enhanced my learning while sharing knowledge with my peers based on current publications and personal experience in the practice setting. I valued this exercise because I had the freedom to design a session that felt most in line with my interests and needs as a learner.

I incorporated items from the clinical setting into my presentation because I wanted my peers to gain a sense of what it was like to practice in sexual health. I created mock charts and examples of diagnostic testing and requisitions to offer my peers tangible items to compliment my content on sexually transmitted infections. I find that reflection seminars are a great space for gaining a solid grasp of other learners' practicum experiences. As we all participate in a variety of settings some of us will never see for ourselves, the reflection sessions offer insight and firsthand stories so that we can gain a greater understanding of the diverse areas in which nurses can practice.

I appreciated receiving evaluations from my peers. They wrote their feedback in a greeting card, commenting on my passion for public health. The feedback reinforced my strengths as a nursing student while enhancing the supportive environment of the reflection sessions and building trust among the group. I think these opportunities for feedback and supporting one another add to the rich discussions and sharing that occur in small groups of adult learners. Further, these feedback exercises relate to what we can expect in the professional setting.

The benefits of conducting my presentation were numerous. I had the opportunity to engage with my preceptor and discuss my ideas with her, and found that she was supportive and interested in the exercise. We worked together to come up with activities and materials for my presentation, her extensive experience in sexual health to be valuable to my final product. We discussed potential case studies and diagnostic testing in detail so that I felt confident that I was relaying accurate information to my peers. This opportunity for collaboration reinforced how instrumental preceptors have been to my success as a nursing student and the fantastic resource they represent in my education. Further, I benefited from assuming a leadership role through group facilitation. This 
exercise allowed me to gain a greater appreciation for the instructor's role in maintaining a schedule and the interest of the group. The presentation offered me the platform to speak on a topic I am interested in. Rather than presenting a topic that was allocated to me by someone else, I had the freedom to select my content, which made me more comfortable with the process and more inclined to present with confidence.

I had the privilege to engage in a student-led maternity presentation from my peer who is a midwife. She used props to enhance her demonstration of the uterus and the labour and delivery process. This student drew from her experiences and offered valuable insights on a topic she was well versed in. She answered questions with confidence and detail, because it was evident that she was in her element and exercising her strengths.

The student-led presentations reinforced our value as adult learners, with diverse experiences that we can all learn from. We are encouraged to incorporate our past knowledge into our current practice, sharing our findings with each other and taking advantage of our collective lifelong learning. The whole group benefits from this strengths-based learning approach.

\section{A LEARNER'S NARRATIVE ON THE DiA- BETES MELLITUS PRESENTATION}

I defined my presentation as strengths-based because I was learning about diabetes every day in my clinical placement. I was exposed to many different resources about diabetes prevention and I was involved in learning and editing the training program. I had experience in previous clinical placements with patients in an acute care setting that were already diagnosed with diabetes mellitus and were managing the disease with insulin or oral medications. I wanted to pull my acute and community experiences together to form a presentation that discussed risk assessment, prevention, diagnostic testing, management and NCLEX practice questions. I felt like my presentation was well received by my co-learners, as the verbal and written feedback I received was positive. Co-learner questions were answered and discussion around certain risk factors arose that our group was able to examine.

Throughout the process of creating my presentation, I was very self-reliant. I had communicated to my preceptor that I was creating the presentation and the information that I was going to research was beyond what I was exposed to in my clinical placement. My preceptor at the time asked me to send her the presentation when I was done in order to help her further develop and refresh her own knowledge. In terms of research, I used my medical-surgical textbook by Lewis, Heitkemper, \& Dirksen (2004) and focused on

Published by Sciedu Press the chapter about Diabetes. ${ }^{[12]}$ I also turned to the International Diabetes Federation website (2016) that I found very helpful throughout my clinical placement. I used this site to gain new knowledge, while also using the quizzes to test my knowledge and understanding of the material.

The challenge while creating this presentation was the magnitude of information regarding diabetes. I had to decide what information was most important and what the gaps were in my own knowledge. By this point in our nursing program, most of my co-learners had general knowledge about diabetes, but I wanted to go into more detail regarding the different types of insulin and the appropriate diagnostic tests that are used. I kept the presentation straightforward by initially conducting a risk assessment with the group, followed by a general overview of the differences between type 1 and type 2 diabetes mellitus. Following this, I went into the clinical manifestations and what to look for in clients who are experiencing symptoms, after which I continued with the diagnostic testing and management. The experience of creating the presentation allowed me to grow my confidence while researching a topic that was relevant to my clinical placement. I was able to share learned information with my preceptor and my co-learners, which gave me the self-assurance I needed. I was on my way to becoming a registered nurse and it felt good.

Not only did I learn from creating and presenting my own material, but listening and participating in my co-learners' presentations was extremely beneficial as well. I was able to learn from co-learners who were immersed in an area of nursing that I had not had the opportunity to see or practice in. I specifically remember learning a lot from a co-learner who discussed oncology in her presentation. It was clear that my co-learner had a passion for oncological nursing and this came across as her main strength. I had very little knowledge on the topic and I was still able to follow along throughout the presentation without feeling lost. The classification of various types of cancer is the part that really stuck in my head and which has allowed me to understand the terms used when discussing patient diagnoses. Although I have never been in an oncology setting, I have had patients with a history of cancer or who have cancer as a co-morbidity. Thinking back, my co-learner's presentation has helped me with these patients and the notes that I took during the presentation have been useful in referring back to.

\section{A LEARNER'S NARRATIVE ON THE ONCO- LOGICAL NURSING PRESENTATION}

The intention of my presentation was to provide my classmates with an opportunity to discover concepts in oncologi- 
cal nursing. We were instructed to present a topic in which we had experience and in which we considered ourselves to be "peer experts". In discussion with my classmates I learned I was the only one with experience on an oncology unit, so my peers expressed interest in hearing about my experiences and in receiving an overview of critical concepts. The information I presented was based on my experience on an inpatient leukemia clinical placement alongside literature found in nursing textbooks and in organizational policy. I chose to present my topic as a 45-minute PowerPoint presentation. The delivery was informal, allowing for questions and discussions based on the learning needs of my peers. Topics which led to further discussion were important aspects of physical assessment, treatment modalities, and psychosocial considerations.

Preparing for this presentation required reflection on what I saw, learned, and did on the unit. I revisited old study notes, sought out relevant NCLEX practice questions that I thought would complement my content, and reviewed common pharmacology. This activity provided the opportunity to explore new aspects of this topic that I had not previously considered; reviewing past learning revealed gaps in knowledge that now, further into the undergraduate program, are apparent to me. I was able to assess how far I had come into my role as a nurse, through the practical knowledge I gained and a heightened awareness of how my attitudes and beliefs have continued to change through my learning journey. In coming so far, I was proud of the content I was able to share in my presentation. My ability to speak to the nursing care leukemia patients require added depth to the information presented; my peers had additional questions based on what I witnessed as a student on the unit. I believe the strength of this presentation was the ability to introduce my peers not only to content, but to a unit of which they had no previous knowledge or experience. They were able to leave with some idea of what oncology nursing care looks and feels like.

Conducting this presentation also helped me garner confidence in public speaking. The process of putting together a presentation and delivering it to an audience is imperative to the nursing role across acute and community settings. Although informal in nature, the opportunity to practice presentation skills and public speaking was beneficial. Realizing that the reflection group is designed to be fundamentally safe and judgement-free, this exercise highlighted the value of peer support specifically through knowledge-sharing: others added to the presentation by openly revealing their knowledge gaps, assumptions, and knowledge from their own experiences. This provided the opportunity for much discussion in an environment where we felt supported and encouraged by one another.
I found immense value in hearing from my peers. For example, one of my peers presented ECG readings which at the time I had minimal exposure to. My peers' presentations offered an opportunity to grow my knowledge base without becoming overwhelmed by content while benefiting from a peer's narrative. I identified "peer leaders" in certain topics that I could later approach for help, clarification or advice. It also helped me get to know my peers better by identifying their interests and strengths.

To describe our strengths-based peer-led presentations, I use the words Relevant, Useful, Leadership, Opportunity, and Collective. The presentations were relevant because they provided information that was either new to me or was a topic which provided a good review for both clinical practice and for preparing for the NCLEX. Some presentations included opportunities to practice skills or gave us exposure to tools important in particular practice areas. The activity allowed us to lead peers in discussion and build on different ideas and experiences. Directing discussion as peers expressed interest in certain areas of the presentation helped practice facilitation skills. It was also a collective experience, one which required participation from both presenter and peer-learners as everyone openly contributed to create a rich learning session.

\section{LESSONS LEARNED}

This strengths-based student-led presentation activity is designed based on teaching experiences and strengths-based theory. The activity is well accepted by students. Understanding the characteristics and benefits of this activity could be meaningful for future nursing education. Through reflection on our learning experiences from this activity, we are able to articulate four themes that impacted our learning journey.

\subsection{Creating a caring and empathetic learning environ- ment}

Starting from a student-centred needs assessment and ending with thank you cards, this learning activity is characterized by its caring and empathetic learning environment. Using strengths-based theory, group members considered themselves and others as people who have strengths to be shared and respected for their expertise and efforts. The learners are in a growing process to be professional nurses requiring care and support. Approaching the nursing journey in a way that celebrates strengths allows for a supportive environment that builds learners up, rather than bringing them down. In our collective learning journey, group members appreciated each other's hard work, showed true interest in each other's learning, cared about each other when encountering difficulties, depended on each other's support to strive for professional 
growth, and celebrated each other's success. This learning environment nurtured a safe, positive, enjoyable, and successful learning journey.

Nursing school in general can be high-stress and nursing students are prone to experiencing anxiety and worry. Nursing students cope with these feelings in a variety of ways such as seeking the support of peers; however, it is reported that a minimal percentage relies on faculty during these trying times. It is suggested that faculty should promote a collaborative and supportive learning environment as a means to offer support to students. ${ }^{[13]}$ Our experiences in this activity are consistent with research findings in current literature. Recent evidence suggested that empathetic teachers have a positive impact on their students' professional development, desire to push forward in their education, and overall quality of life. ${ }^{[14]}$ Conversely, teachers who do not incorporate empathy in their teaching can have negative effects. Another study also indicated that faculty could have a meaningful impact and develop a trusting bond with their students by demonstrating an authentic interest in their success. ${ }^{[15]}$ Caring environments promote understanding and learning. Students felt safe in an environment that was free of judgement, fostering confidence and a sense of encouragement. ${ }^{[16]}$ In the nursing profession, which relies on caring and empathy as major tenets of its identity, ${ }^{[17]}$ it is beneficial to incorporate caring and empathy to build a supportive learning environment for future nurses. ${ }^{[18]}$

\subsection{An open self-directed curriculum design}

The strengths-based student-led presentation activity reflects an open curriculum design where students are empowered to collaboratively drive their learning by their own desires. ${ }^{[19-21]}$ Each student facilitated a session according to their interests and strengths in nursing. There was no limitation on content, presentation format, or timeframe. Through group negotiation, students chose topics that reflected their strengths and satisfied others' needs. Collectively, we had an understanding that our co-learners may possess varying levels of knowledge on each topic, so we emphasized an open floor for questions that nurtured rich discussion and support. There is a sense of comfort with other learners, which initiates interaction and dialogue. ${ }^{[22]}$ By working together and learning from each other, we lessen the power dynamic that occurs between faculty and students, and students were empowered to be in the driver's seat of their education. This activity can be described as empowering and collaborative. Our experiences are consistent with current literature, which suggests that students and educators can work together to identify strengths and determine the trajectory of the learning process. A technique to incorporate the strengths perspective in a way that is "empowering" is to offer students the opportunity to lead a session using skills and knowledge from the practice setting. ${ }^{[9]}$ Furthermore, evidence suggested that empowered students tend to be successful in school and after graduation. ${ }^{[23]}$

Since this learning activity is open and self-directed, learners are able to use this opportunity to facilitate their own learning goals, which may include practice for the National Council Licensure Examination (NCLEX). The NCLEX has been identified as a challenge for current nursing students in Ontario, Canada. ${ }^{[24]}$ Using this learning opportunity, each presenter selected NCLEX style questions related to their topics. By this approach, students could apply their knowledge to a format that they will encounter when writing their licensing exams. Students worked through the questions collaboratively and discussed rationales with the support of the facilitator. Students were able to apply their distinct experiences to each question, drawing from each other's knowledge to come to conclusions. This application reinforced existing knowledge and identified gaps in specific areas.

As an open self-directed curriculum design, the instructor did not require that students should include peer-reviewed literature in their presentations. As a result, it was found that our student-led presentations tended to use textbooks, hospital policies, and webpages as evidence and lacked references to peer-reviewed literature. Using peer-reviewed literature should be a must for any undergraduate program and presentation. ${ }^{[25]}$ In future, including peer-reviewed literature should be listed as a recommendation for this student-led activity. The instructor should guide students to actively search for evidence, criticize current literature, and gain new insights from collegial engagement.

\subsection{Reciprocal learning}

Different from traditional teaching, which involves the transfer of information from instructor to students, this learning activity supported all participants, including faculty, students and preceptors, to teach, learn and benefit. Students and the instructor could benefit from individual experiences and insights. Students were essentially exchanging information about topics that they either knew well or wanted to know well. Students were able to discuss the topics conversationally and learned from each other. Faculty and students were directly involved in this learning activity, while preceptors indirectly participated by providing information, demonstrating clinical skills and offering feedback. Preceptors, as expert nurses, are apt to identify and evaluate problems; nursing students are skilled in locating evidence and finding literature. A collaborative relationship between students and their preceptors is beneficial to both parties. ${ }^{[26]}$ For students, peer 
educating led to the development of teaching skills as well as high personal rewards; ${ }^{[27]}$ for preceptors, they feel appreciated, were recognized for their expertise, and experienced high job satisfaction. ${ }^{[7]}$ This activity provides a learning network, where all learners come together in a stimulating learning community. This network connects various strengths and allows the learning benefits to flow in several directions.

\subsection{Leadership to influence peers and practicum}

The strengths-based student-led presentations offered a smallscale leadership opportunity for all members of the group. Each student was given a set period of time to direct learning in the way they felt most appropriate. They directed the flow of the reflection seminar, provided learning tools and materials, and facilitated discussions. This learning activity offered a platform to build self-confidence, to encourage meaningful reflection, and to hone leadership skills in a safe space with familiar peers. Current literature suggested that a safe non-hierarchical learning environment promotes leadership skills. ${ }^{[28]}$ Strengths-based student-led presentations are a valuable strategy for incorporating the strengths-based framework to benefit nursing undergraduates as they transition from roles in education to clinical practice. Further, the exercise prepares graduates to be nursing leaders in the future.

\section{IMPLICATIONS TO NURSING EDUCATION}

Strengths-based student-led presentations can be an alternative learning activity to reach Dool's 4Rs: richness, recursion, relations and rigor. Using an open self-directed curriculum design, students maximize their choices for engaging content according to their interests. Through peer-led learning, this activity challenges students to reflect on past experiences and current learning with deeper insight. Students strive to merge their learning gaps by reflecting on content and experiences while solidifying their knowledge through peerteaching. ${ }^{[29,30]}$ By building a caring learning environment, students are able to relate their learning to others and develop a personal understanding about the nursing profession.

Our experiences indicate that a strengths-based approach could be an effective and innovative learning strategy. This strategy can be applied in different educational settings with various nursing populations. In acute care settings a strengths-based approach can be used in professional development events, where professional nurses who are experts in particular areas can share their learning with other nurses on the unit. ${ }^{[31]}$ In addition, strengths-based learning can be applied at the interprofessional level in health care professional education. For example, nursing students were successful with patient transfers and manual handling after learning these skills from fourth year physiotherapy students. ${ }^{[22]}$ Healthcare professionals can adopt the strengths-based learning process by collaborating and sharing knowledge from their respective specialties. Finally, a strengths-based peerled approach can be used for health education in the community. For instance, peer-led diabetes education in a homeless community was successful in transferring knowledge and empowering participants. ${ }^{[32]}$ Our experiences and narratives could provide some insights that stimulate future researchers to study the effects of strengths-based nursing theory application in nursing education using rigorous study designs.

\section{CONFLicts OF InTEREST Disclosure}

The authors declare that there is no conflict of interest.

\section{REFERENCES}

[1] Allin S, Grignon M, Wang L. The determinants of efficiency in the Canadian health care system. Health Econ Policy Law. 2016; 11(1): 39-65. PMid:25998743 https://doi .org/10.1017/S174 4133115000274

[2] Wallis L. Canadian commission calls on nurses to be a force for change. Am J Nurs. 2012; 112(9): 17. https://doi .org/10.109 7/01.NAJ.0000418911.10161.e8

[3] Doll WJ. A Post-Modern Perspective on Curriculum. New York: Teachers College Press; 1993.

[4] Zarins B, Carter L, McParland T. An Innovative Approach to Adult Education in a Two-year BScN Program: Creating Partnerships in Learning. Quality Advancement in Nursing Education. 2015; 1(2): 16. https://doi.org/10.17483/2368-6669.1025

[5] Glynn DM. Clinical judgment development using structured classroom reflective practice: a qualitative study. J Nurs Educ. 2012;
51(3): 134-9. PMid:22283156 https ://doi .org/10.3928/0148 4834-20120127-06

[6] Green BN, et al. Use of a clinical seminar to horizontally integrate basic science and clinical topics for year-one students. J Allied Health. 2008; 37(3): e160-76. PMid:19753396

[7] Gottlieb LN, Gottlieb B, Shamian J. Principles of strengths-based nursing leadership for strengths-based nursing care: a new paradigm for nursing and healthcare for the 21 st century. Nurs Leadersh (Tor Ont). 2012; 25(2): 38-50. https ://doi .org/10.12927/cjnl . 20 12.22960

[8] Gottlieb LN. Strengths-based nursing. Am J Nurs. 2014; 114(8): 24-32; quiz 33,46.

[9] Cederbaum J, Klusaritz HA. Clinical instruction: using the strengthsbased approach with nursing students. J Nurs Educ. 2009; 48(8): 4228. PMid:19681530 https://doi .org/10.3928/01484834-200 90518-01

[10] Clandinin DJ. Handbook of Narrative Inquiry: Mapping a Methodol- 
ogy. Thousand Oaks: CA: Sage; 2007. https://doi .org/10.413 5/9781452226552

[11] Connelly FM, Clandinin DJ. Narrative Inquiry, in Handbook of Complementary Methods in Education Research, G. Green, et al., Editors. Lawrence Erlbaum Associates: Washington, DC. 2006; 477-487 P.

[12] Lewis SM, Heitkemper MM, Dirksen SR. Medical-Surgical nursing (6th ed.). St. Louis, MO: Mosby; 2004.

[13] Reeve KL, et al. Perceived stress and social support in undergraduate nursing students' educational experiences. Nurse Educ Today. 2013; 33(4): 419-24. PMid:23246284 https ://doi .org/10.101 $6 / j$.nedt. 2012.11.009

[14] Mikkonen K, Kyngas H, Kaariainen M. Nursing students' experiences of the empathy of their teachers: a qualitative study. Adv Health Sci Educ Theory Pract. 2015; 20(3): 669-82. PMid:25266998 https://doi.org/10.1007/s10459-014-9554-0

[15] Hutchinson TL, Janiszewski Goodin H. Nursing student anxiety as a context for teaching/learning. J Holist Nurs. 2013; 31(1): 19-24. PMid:23065057 https://doi.org/10.1177/08980101124620 67

[16] White P, Rowland AB, Pesis-Katz I. Peer-led team learning model in a graduate-level nursing course. J Nurs Educ. 2012; 51(8): 471-5. PMid:22766075 https://doi.org/10.3928/01484834-20120 706-03

[17] Watson J. Caring science and human caring theory: transforming personal and professional practices of nursing and health care. J Health Hum Serv Adm. 2009; 31(4): 466-82. PMid:19385422

[18] Watson J. Social justice and human caring: A model of caring science as a hopeful paradigm for moral justice for humanity. Creat Nurs. 2008; 14(2): 54-61. PMid:18655513 https://doi.org/10.189 $1 / 1078-4535.14 .2 .54$

[19] Phillips BN, Turnbull BJ, He FX. Assessing readiness for selfdirected learning within a non-traditional nursing cohort. Nurse Educ Today. 2015; 35(3): e1-7. PMid:25620290 https ://doi .org/10 $.1016 / j$.nedt .2014 .12 .003

[20] Shirazi F, et al. Dynamics of self-directed learning in M.Sc. nursing students: A qualitative research. J Adv Med Educ Prof. 2017; 5(1): 33-41. PMid:28124019

[21] Slater CE, Cusick A. Factors related to self-directed learning readiness of students in health professional programs: A scoping review. Nurse Educ Today. 2017; 52: 28-33. PMid:28229917 https : //doi.org/10.1016/j.nedt.2017.02.011
[22] McCrorie P, et al. Perceptions of Nursing and Physical Therapy Students Toward Peer-Led Interprofessional Education in Manual Handling. Nurse Educ. 2017; 42(1): E1-E6. PMid:27580303 https://doi.org/10.1097/NNE.0000000000000319

[23] Moore SC, Ward KS. Nursing Student Perceptions of Structural Empowerment. Nursing Education Perspectives. 2017; 38(1): 2.

[24] McGillis Hall L, Lalonde M, Kashin J. People are failing! Something needs to be done: Canadian students' experience with the NCLEX-RN. Nurse Educ Today. 2016; 46: 43-49. PMid:27592381 https://doi.org/10.1016/j.nedt.2016.08.022

[25] Moch SD, Cronje RJ, Branson J. Part 1. Undergraduate nursing evidence-based practice education: envisioning the role of students. J Prof Nurs. 2010; 26(1): 5-13. PMid:20129587 https: //doi.org/10.1016/j.profnurs.2009.01.015

[26] de Cordova PB, et al. Implementing evidence-based nursing with student nurses and clinicians: uniting the strengths. Appl Nurs Res. 2008; 21(4): 242-5. PMid:18995169 https://doi.org/10.101 6/j.apnr.2008.06.008

[27] McKenna L, French J. A step ahead: teaching undergraduate students to be peer teachers. Nurse Educ Pract. 2011; 11(2): 141-5. PMid:21051284 https://doi.org/10.1016/j.nepr.2010.10 .003

[28] Ha L, Pepin J. Experiences of nursing students and educators during the co-construction of clinical nursing leadership learning activities: A qualitative research and development study. Nurse Educ Today. 2017; 55: 90-95. PMid:28544985 https ://doi.org/10.1016/j. nedt. 2017.05.006

[29] Williams B, Olaussen A, Peterson EL. Peer-assisted teaching: An interventional study. Nurse Educ Pract. 2015; 15(4): 293-8. PMid:25866358 https://doi.org/10.1016/j.nepr.2015.03 .008

[30] Zentz SE, Kurtz CP, Alverson EM. Undergraduate peer-assisted learning in the clinical setting. J Nurs Educ. 2014; 53(3): S4-S10. https://doi.org/10.3928/01484834-20140211-01

[31] Gardner S. Improving Staff Satisfaction Through Peer-Led Professional Development. Gastroenterol Nurs. 2016; 39(2): 96-100. PMid:27070793

[32] Davis S, et al. A Peer-led Diabetes Education Program in a Homeless Community to Improve Diabetes Knowledge and Empowerment. J Community Health Nurs. 2016; 33(2): 71-80. PMid:27074403 https://doi.org/10.1080/07370016.2016.1159435 